\title{
DEMÜTIGUNG, EHRE, HELDENGEDENKEN. DER SCHRIFTSTELLER PAUL COELESTIN ETTIGHOFFER ZWISCHEN SOLDATISCHEM NATIONALISMUS UND NATIONALSOZIALISMUS
}

\author{
BERND F. W. SPRINGER \\ Universitat Autònoma de Barcelona \\ bernd.springer@uab.cat \\ ORCID: 0000-0003-4581-8183
}

\section{ZUSAMMENFASSUNG}

Der Artikel arbeitet auf vier verschiedenen Ebenen heraus, wie, wann und warum ein dem Ehrenkodex des alten Kaiserreiches verhafteter Veteran und Kriegsromanautor sich für die mentale Kriegsvorbereitung der Nazis einspannen ließ. Dabei wird die These aufgestellt, dass er keine spezifisch ideologische Affinität zum Nationalsozialismus aufwies, sondern dass der Veteranenkult der Nazis ein emotionales Bedürfnis bediente, das die offizielle Gedenkpolitik der Weimarer Republik vernachlässigt hatte.

SCHLÜSSELWÖRTER: Frontromane, soldatischer Nationalismus, Nationalsozialismus, Veteranenkult, Heldengedenken, Gefühlsgeschichte.

\section{HUMILIATION, HONOR, HEROES MEMORY. THE WRITER PAUL COELESTIN ETTIGHOFFER BETWEEN SOLDIER NATIONALISM AND NATIONAL SOCIALISM}

\section{ABSTRACT}

The article examines on four different levels, how, when and why a First World War veteran and novelist, who felt committed to the code of honour of the old empire, could be involved by the Nazis in their mental preparation for Second World War. The thesis is that he had no specific ideological affinity for National Socialism, but that the veteran cult of the Nazis served an emotional need that had been neglected by the official memorial policy of the Weimar Republic.

KEYWORDS: Front novels, soldier nationalism, National Socialism, veteran cult, heroes memory, history of emotions.

Der Schriftsteller Paul Coelestin Ettighoffer (1896-1975) ist ein hoch interessantes Beispiel dafür, wie und warum ein zunächst humanistisch in Erscheinung tretender Kriegsbuchautor, dessen autobiografischer Roman über den 1. Weltkrieg Gespenster am Toten Mann streckenweise an Remarques Im Westen nichts Neues erinnert, sich in sehr kurzer Zeit der Nachfrage auf dem Büchermarkt des Dritten Reiches anpasste und auf einen Kurs mentaler Kriegsvorbereitung einschwenkte. Anders gesagt: warum ein dem Ehrenkodex des alten Kaiserreiches verhafteter Veteran in das nationalsozialistische Führerlob einstimmte. 
Die Gründe dafür liegen auf mindestens vier Ebenen. Erstens ging es für den Schriftsteller, der 1931/32 zum Erfolgsautor avanciert war, um die thematische Anpassung an einen sich rasant verändernden Buchmarkt, der ab 1933 von den NS-Machthabern übernommen, kontrolliert und gelenkt wurde. Zweitens gehörte zu dieser ,Lenkung' die ideologische Beeinflussung und der Druck durch Schriftstellerkollegen wie etwa denen der ,Mannschaft', deren Wortführer dazu aufforderten, sich $\mathrm{zu}$ positionieren und die eigenen Erfahrungen ,in den Dienst des Vaterlandes‘ zu stellen. Drittens ging es um mentale Einstellungen, die noch aus der autoritären Sozialisation im Kaiserreich und aus dem Krieg stammten, wie z.B. das Führerprinzip oder das binäre Freund-Feind-Denken. Sie ließen sich nur unter Schwierigkeiten mit den neuen Erfordernissen einer parlamentarischen Demokratie vereinbaren und hatten eine ,natürliche Affinität' zum Führerprinzip der Nationalsozialisten. Und viertens ging es bei jemandem wie Ettighoffer ganz wesentlich auch um Gefühle, wie z.B. Ehre, Ruhm und Anerkennung, die ebenfalls nichts mit dem Nationalsozialismus zu tun hatten, von ihm aber perfekt bedient wurden.

Auf diesen vier Ebenen wird im Folgenden die Stellung Ettighoffers zwischen dem so genannten ,soldatischen Nationalismus' und dem Nationalsozialismus untersucht.

Um die genaue Entwicklung der politischen Ansichten Paul Coelestin Ettighoffers nachzeichnen zu können, wäre es nützlich, über weit mehr biografische Detail-Informationen zu verfügen als dies tatsächlich der Fall ist. Das gilt sowohl für die Prägungen seiner Jugend, wie auch für seine Tätigkeiten und sozialen Kontakte in der Weimarer Republik und vor allem für seine Haltung zum Nationalsozialismus. Da sein Privatarchiv zusammen mit seinem Haus 1944 bei einem Bombenangriff zerstört wurde, ist es nicht mehr möglich, etwa durch briefliche Korrespondenzen oder Tagebücher Aufschlüsse über seine politischen Ansichten zu ganz konkreten Zeitpunkten zu gewinnen. ${ }^{1}$ Der vorliegende Artikel versucht daher, Ettighoffers Haltung zum Nationalsozialismus anhand seiner Publikationen bis einschließlich $1938 \mathrm{zu}$ rekonstruieren.

\section{BIOGRAFISCHE ANNÄHERUNG: DIE „BITTEREN JAHRE DER ZWISCHENZEIT“}

Ettighoffer wurde am 1896 in Colmar im Elsass, das damals zum Deutschen Reich gehörte, geboren. Er entstammte einer altelsässischen Bauernfamilie, verlor aber offenbar früh seine Eltern, denn er wuchs zunächst bei seinen Großeltern, dann in einem Waisenhaus auf. Gönner, über die wir ebenfalls keine weiteren Informationen besitzen, ermöglichten ihm schließlich den

\footnotetext{
12004 trug Andreas Lampert die noch verfügbaren Informationen über das Leben des Autors in einem Artikel auf der Datenbank Polunbi zusammen: <http://www.polunbi.de/pe rs/ettighoffer-01.html>.
} 
Besuch eines kostenpflichtigen Jesuitengymnasiums im belgischen Mons. Neben einer humanistischen Bildung lernte er dort offenbar auch den Sprachen- und Identitätskonflikt kennen, der Belgien seit seiner Loslösung zunächst von den Habsburgern und dann von den Niederlanden prägte. Man kann nur vermuten, dass er sich in einer Umgebung, in der wallonische und flämische Identitätsansprüche konkurrierten, seiner eigenen Fremdheit in diesem Konflikt früh bewusst wurde und sich innerlich, durch welche Einflüsse und Kontakte auch immer bestärkt, der deutschen Nationalität zugehörig fühlte. Jedenfalls trat er nach dem Abitur 1914 achtzehnjährig als Kriegsfreiwilliger in die deutsche Armee ein, wo er sich, "gewohnt an ein Leben in Institutionen", offenbar "gut zurechtgefunden zu haben" scheint. ${ }^{2}$

Ende 1914 wurde er verwundet, im Frühjahr 1915 nahm er an der Champagne-Schlacht auf der Lorettohöhe teil, wurde erneut verwundet, erhielt nach seinem Lazarettaufenthalt eine Scharfschützenausbildung und wurde im Mai 1916 an die Ostfront verlegt. Anfang 1917 kam er wieder an die Westfront, zunächst nach Verdun, wo die blutige Schlacht um das Festungswerk allerdings bereits beendet war. Bei einer Rückzugssicherungsoperation gegen Ende der letzten großen Marne-Offensive im Sommer 1918 geriet er, bis dahin mehrfach ausgezeichnet, schwer verwundet in französische Kriegsgefangenschaft. Nach zwei fehlgeschlagenen Fluchtversuchen wurde er erst im Februar 1920 nach Deutschland ausgeliefert.

Wie viele Heimkehrer seiner Generation, die ohne Berufsausbildung von der Schulbank an die Front gingen und deren Lebenserfahrungen unmittelbar nach der Volljährigkeit von extremer und traumatisierender Gewalt bestimmt waren, hatte auch er große Schwierigkeiten, sich in dem von politischen, sozialen und wirtschaftlichen Krisen geprägten Nachkriegsdeutschland zurechtzufinden. Sofern seine autobiografische Darstellung Zelt 27 wird niedergerissen zutreffend ist, hat er als Mitglied der Sicherheitspolizei an der Niederschlagung des Ruhraufstandes nach dem Kapp-Putsch im März 1920 teilgenommen. Dieser Bericht, der allerdings erst 1933 erschien, zeichnet sich durch einen militanten Kommunistenhass aus. Ihm ist auch zu entnehmen, dass Ettighoffer sich nach 1920 vermutlich als Verkäufer und Reisevertreter mehr schlecht als recht durchzuschlagen versuchte. Ende der 1920er Jahre arbeitete er dann als Reporter beim Kölner Stadtanzeiger, der 1931 seine LandstreicherReportage Servus Kumpel abdruckte.

1937 bezeichnete Ettighoffer diese Erfahrungen in der Weimarer Republik

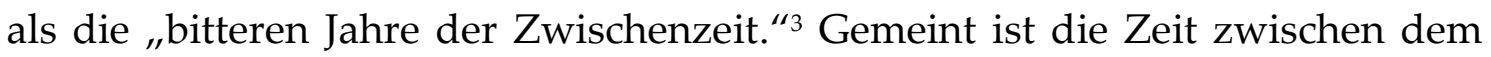
Ende des 1. Weltkriegs und der Machtergreifung Hitlers. Für Ettighoffer stellen sich diese „bitteren Jahre“ als eine Zeit dar, in der weder die soldatische noch die nationale Ehre eine als ,gebührend' betrachtete Anerkennung erfuhren. Die

\footnotetext{
2 Lampert, Artikel „Ettighoffer“, auf polunbi.

${ }^{3}$ Ettighoffer (1937b: 55).
} 
Formulierung drückt ein Leiden am Zeitgeist aus, das sowohl politisch (nationale Demütigung durch die "Schmach“ und den „Verrat" von Versailles) als auch persönlich (Orientierungslosigkeit des Veteranen im zivilen Leben) motiviert ist. Der Kontext der zitierten Stelle zeigt, wie sehr der Autor das Ende dieser "Zwischenzeit", konkret die Aufrüstung der Wehrmacht seit $1935^{4}$ begrüßte:

Draußen marschiert unsere junge, stolze Wehrmacht. Infanterie marschiert vorbei. Und ich stehe am Fenster und blicke hinab, und mein Herz springt vor Freude. [...] Und ich freue mich, daß alles wieder so ist, wie es früher war [...], und wie wir es in den bitteren Jahren der Zwischenzeit erstrebt und mit heißem Herzen erträumt hatten. Nein, es ist vieles noch besser als früher. ${ }^{5}$

Spätestens mit dieser 56 Seiten langen Werbeschrift für die Infanterie, einer Art geistiger Mobilmachung, war Ettighoffer 1937 auf den Kurs eines Kriegspropagandisten eingeschwenkt. Aber war er ein Nazi?

\section{Die Haltung ZUM Nationalsozialismus}

Nach dem 2. Weltkrieg erließen die Siegermächte am 13.5.1946 den Befehl Nr. 4 des Kontrollrats, der die „Einbeziehung von Literatur und Werken nationalsozialistischen und militaristischen Charakters" betraf. Diese Zensurliste umfasste über 30.000 Titel. Von Ettighoffer stehen folgende Titel auf der Liste: ${ }^{6}$

6015. Ettighoffer, Paul Coelestin: Bewährung, Düsseldorf: Bagel, 1941.

6016. Ettighoffer, Paul Coelestin: Deutsche Tanks fahren in die Hölle, Gütersloh: Bertelsmann, 1937.

6017. Ettighoffer, Paul Coelestin: Erschossen zu Nanzig, Straßburg: Hünenburg-Verl., 1942. 6018. Ettighoffer, Paul Coelestin: Feldgrau schafft Dividende, Köln: Gilde-Verl., 1932.

6019. Ettighoffer, Paul Coelestin: Elsässischer Feldgrauer, Straßburg: Hünenburg-Verl., 1942.

6020. Ettighoffer, Paul Coelestin: Das gefesselte Heer, Gütersloh: Bertelsmann, 1941.

6021. Ettighoffer, Paul Coelestin: Heiß die Segel, Köln: Bachem, 1935.

6022. Ettighoffer, Paul Coelestin: Die Infanterie marschiert, Dortmund: Crüwelt, 1937.

6023. Ettighoffer, Paul Coelestin: Kameraden vom Zelt 27, Gütersloh: Bertelsmann, 1939.

6024. Ettighoffer, Paul Coelestin: Die Lene beißt sich durch, Düsseldorf: Bagel, 1937.

6025. Ettighoffer, Paul Coelestin: Moskau, Compiegne, Versailles, Gütersloh: Bertelsmann, 1936.

6026. Ettighoffer, Paul Coelestin: Nacht über Sibirien, Gütersloh: Bertelsmann, 1943.

6027. Ettighoffer, Paul Coelestin: So sah ich Afrika. Mit Auto u. Kamera durch unsere Kolonien, Gütersloh: Bertelsmann, 1943.

\footnotetext{
${ }^{4}$ 16. März 1935: Gesetz über den Aufbau der Wehrmacht und Wiederherstellung der Wehrhoheit und Einführung der allgemeinen Wehrpflicht zum 1. Oktober 1935.

${ }^{5}$ Ettighoffer (1937b: 55).

${ }_{6}^{6}$ Online unter: <https://archive.org/stream/UnbekanntAlliierteZensurImNachkriegsdeutschl and/Unbekannt\%20-\%20Alliierte\%20Zensur\%20im\%20Nachkriegsdeutschland_djvu.txt>.
} 
6028. Ettighoffer, Paul Coelestin: Der unbekannte Soldat, Bielefeld: Leipzig: Veuiagen \& Klasing, 1941.

6029. Ettighoffer, Paul Coelestin: Das Soldatentum der Schwester Käthe, Düsseldorf: Bagel, 1937.

6030. Ettighoffer, Paul Coelestin: Dem Stacheldraht entronnen, Gütersloh: Bertelsmann, 1939.

6031. Ettighoffer, Paul Coelestin: Von der Teufelsinsel zum Leben, Gütersloh: Bertelsmann, 1942.

6032. Ettighoffer, Paul Coelestin: Wirst du einst Rekrut ..., Köln: Bachem, 1935.

6033. Ettighoffer, Paul Coelestin: Zelt 27 wird niedergerissen, Leipzig: Strackmann, 1933.

6034. Ettighoffer, Paul Coelestin: Zug der Letzten, Dortmund: Crüwell, 1936.

„Militaristischen“ bzw. soldatischen Charakters sind viele dieser Werke. Bei einigen Büchern muss man allerdings andere Motive für ihr Verbot vermuten, so etwa bei Feldgrau schafft Dividende, das die Leiden und Schikanen in französischer Kriegsgefangenschaft behandelt oder bei Elsässischer Feldgrauer, in dem die Treue und Verlässlichkeit der Elsässer Soldaten zu Deutschland betont werden. Auch bei Zelt 27 wird niedergerissen, wo es um die Nachkriegserfahrungen und die Niederschlagung des Ruhr-Aufstandes geht, kann man die Beweggründe für ein Verbot in der Darstellung der Ruhrbesetzung 1923 durch französische Truppen und die positive Erwähnung des aktiven Widerstandes (der von den Franzosen zum Tode verurteilte Schlageter kommt als aufrechter Widerstandskämpfer vor) vermuten.

In den drei genannten Beispielen liegen die Motive für die Zensur also eher auf der Ebene politischer Unerwünschtheit seitens der französischen Besatzung, als dass sich diese Werke durch „nationalsozialistischen und militaristischen" Charakter auszeichnen würden.

Noch interessanter ist aber, welche Werke nicht auf dieser Liste stehen, obwohl sie sehr wohl soldatischen und auch militaristischen Charakters sind. Es sind dies vor allem Ettighoffers Bücher über den 1. Weltkrieg, mit denen er ab 1931 zum Erfolgsautor avancierte:

Gespenster am Toten Mann, Köln: Gilde, 1931.

Verdun. Das große Gericht, Gütersloh: Bertelsmann, 1936.

Sturm 1918. Sieben Tage deutsches Schicksal, Gütersloh: Bertelsmann, 1938.

Tannenberg. Eine Armee wird zu Tode marschiert, Gütersloh: Bertelsmann, 1939.

Interessant ist diese Auslassung vor allem deswegen, weil die Verarbeitung des 1. Weltkrieges, die Ettighoffer als Veteran, Frontschriftsteller und Repräsentant des soldatischen Nationalismus leistete, trotz ihres forcierten Heroenkultes von den Alliierten offenbar nicht als anstößig wahrgenommen wurde. Das wiederum legt nahe, dass die soldatischen Werte, die in diesen Büchern beschworen wurden und die schon eher geeignet gewesen wären, den Vorwurf einer geistigen Vorbereitung des 2. Weltkriegs zu erheben, damals einem internationalen Zeitgeist entsprachen, der bei den Siegermächten gang und gäbe war. Es kann im Kontext der Bewertung soldatischer Tugenden nicht 
oft genug daran erinnert werden, dass das so genannte ,postheroische Zeitalter ${ }^{4}$ erst nach dem 2. Weltkrieg einsetzte und dies zudem bei den Siegern keineswegs in einem mit Deutschland vergleichbaren Maße geschah - obwohl es natürlich schon vor und erst recht nach dem 1. Weltkrieg pazifistische Reaktionen auch bei den Siegermächten gab.

Die Frage nach Ettighoffers Haltung zum Nationalsozialismus wurde in der Presse erörtert, als es 1980, fünf Jahre nach seinem Tod, zum Streit um die Benennung einer Straße in Euskirchen nach dem Schriftsteller kam. Mitglied der NSDAP war er offenbar nicht und er gehörte auch nicht zu den Schriftstellern, die im Oktober 1933 Adolf Hitler "treue Gefolgschaft“ gelobten. Allerdings war er Mitglied der ,Mannschaft', einer Gruppe von Frontschriftstellern, die sich ab 1934/35 regelmäßig trafen, um Kriegserlebnisse auszutauschen. Sie gab zwischen 1936 und 1939 sechs Anthologien über den Front-Alltag heraus. Nicolas Beaupré hat aufgezeigt, wie diese ,Mannschaft' in dem genannten Zeitraum, gleichgeschaltet', das heißt, auf Ns-Linie gebracht wurde $^{7}$ (dazu weiter unten Genaueres).

1975 wurde Ettighoffer von Frankreichs Staatspräsident Valery Giscard d'Estaing zum Colloque Internationale in Verdun eingeladen, wo er einen Vortrag hielt, der die Zuhörer laut Comité National de Souvenir de Verdun "tief bewegt" haben soll. In der Diskussion um die Straßenbenennung veröffentlichte dieses Comité einen Leserbrief, in dem es heißt:

Als Friedensapostel zwischen unseren beiden Völkern, als Militär-Geschichtler und Veteran hat Ettighoffer mit seinem Werk, das er im Glauben an die Zukunft und in Treue zu seinen Schicksalsgenossen verfasst hat, die damalige internationale Kundgebung in Verdun stark geprägt. ${ }^{8}$

1976 wurde sein Buch Verdun - das große Gericht mit einem Nachwort von Maurice Genevoix, Ehrenmitglied der Académie Française, neu aufgelegt, in dem er den tiefen und leidenschaftlichen Humanismus Ettighoffers herausstellte.

Wenn es richtig ist, dass "die genuinen Ns-Romane $[\ldots]$ meist Propagandaromane [waren], die allein der Propagierung der Ns-Ideologie, des Führerkultes, des Antisemitismus und der totalen Mobilmachung dienten, ${ }^{\prime 9}$ dann kann man mit Sicherheit festhalten, dass Ettighoffer nicht dazu gehörte. Ebenso sicher gehört er aber zu den Autoren, "die beispielhaft für die Kontinuität in der Kriegsliteratur von der Weimarer Republik zum ,Dritten Reich' stehen. ${ }^{\prime 10}$ In dieser Kontinuität knüpfte die nationalsozialistische an die deutschnationale Tradition an. Um vorschnellen Identifizierungen von Autoren des soldatischen Nationalismus mit der Ns-Literatur vorzubeugen, stellt sich

\footnotetext{
${ }^{7}$ Vgl. Beaupré (2010).

${ }^{8}$ Zitiert bei Arntz, „Der Schriftsteller Ettighoffer".

${ }_{9}$ Schneider, T. (2004: 87).

${ }^{10}$ Schneider, T. F. (2008: 13).
} 
dann aber die „Frage, was denn eigentlich [...] bei der Kriegsliteratur [...] spezifisch nationalsozialistisch ist. "11

Was den Schriftsteller Ettighoffer angeht, so lässt sich an dieser Stelle bereits vorwegnehmen, dass an seinen Werken so gut wie nichts spezifisch nationalsozialistisch ist, dass er seine soldatisch-nationalistische Haltung aber sehr wohl in den Dienst des neuen Regimes stellte. Spiegel-Herausgeber Augstein kam auf Anfrage (im Kontext des Streits um den Straßenamen) zu dem Ergebnis, dass man nach den Spiegel-Archiven keinen Anlass habe, Ettighoffer „etwa als NS-Autor zu verstehen. Es kann nicht gesagt werden, dass Ettighoffer zum Aufstieg des Nationalsozialismus beigetragen habe, wohl aber, dass der Heroenkult mancher Verdun-Autoren von diesem Nationalsozialismus ge- und missbraucht wurde. " ${ }^{12}$

Was Ettighoffer angeht, kann man nicht sagen, dass er widerwillig von den Nazis „missbraucht" worden wäre, er hat sich ab 1937 vielmehr aktiv in den Dienst geistiger Mobilmachung gestellt und seine Autorität als Veteran und Erfolgsautor mit einem deutlichen Führerlob verbunden. Das war keine erzwungene, sondern eine freiwillige Anpassung. Die Frage ist, wie es dazu kam.

\section{ANPASSUNG AN DEN NEUEN BÜCHERMARKT IM NATIONALSOZIALISMUS}

Die Anpassung Ettighoffers an den Büchermarkt in der Mitte der 30er Jahre ist eng verbunden mit dem Aufstieg des Bertelsmann-Verlags. Ursprünglich hatte sich der Verlag seit seiner Gründung 1835 durch Carl Bertelsmann auf protestantische Erbauungsliteratur spezialisiert und verstand sich als „Bastion gegen die Gottlosigkeit der Moderne“ und als "Sprachrohr einer gemeinschaftsbezogenen, antiliberalen Kirchlichkeit, die im monarchischautoritären Staat das Fundament der weltlichen Ordnung erblickte. "13 Ende der zwanziger Jahre hatte Heinrich Mohn, Verlagserbe in vierter Generation und bis 1924 Mitglied der DNVP, dem Sammelbecken der alten Eliten des kaiserlichen Deutschlands und des konservativen Protestantismus, mit einer Erweiterung des Verlagsprogramms hin zur Belletristik begonnen. Dies war eine Reaktion auf eine allgemeine Bücherkrise in der Weimarer Republik, in der sich der Abstieg des gebildeten Bürgertums nach dem 1. Weltkrieg widerspiegelte. 1934 gelang dann mit W. von Langsdorffs Flieger am Feind, dem so genannten ,Weihnachtsbuch der Hitlerjugend', ein durchschlagender Erfolg. Seit dem Machtantritt der Nazis eröffnete sich mit deren Gedenkkultur und den zugehörigen Gedenkbänden, in deren Zentrum die Gefallenen des 1. Weltkriegs und bald auch jene der NS-Bewegung standen, ein neuer Markt, und zwar nicht

\footnotetext{
${ }^{11}$ Krumeich, G. (2010: 14).

12 Zitiert in: Arntz, „Der Schriftsteller Ettighoffer”.

${ }^{13}$ Friedländer, Frei, Rendtorff, Wittmann (2002: 551).
} 
in erster Linie für Kriegsbücher generell, sondern speziell für Kriegserlebnisbücher:

In immer neuen Gedenktagen erinnerte das Regime an die Ereignisse des Ersten Weltkrieges - hier lag die Zeit eines Scheiterns, das sich nicht wiederholen durfte, eine Zeit größter Ambitionen der Nation und zudem die Zeit, über die sich die Männer um Hitler öffentlich definierten. ${ }^{14}$

In dieses Geschäft stieg Bertelsmann ab 1934 äußerst erfolgreich ein: „Von 1935 bis 1943 konnte das Unternehmen den Umsatz seiner Belletristik um das Zwanzigfache steigern“ und wurde zum Marktführer „unter den 130 Verlagen, die im Zweiten Weltkrieg im Auftrag der Wehrmacht Lesestoff für die Soldaten an der Front lieferten. ${ }^{\prime 15}$

In diesem Kontext - Bücher, die das eigene, authentische Erleben des Krieges verarbeiteten - wurden Ettighoffers autobiografische Bücher neu verlegt und teilweise in ihren Titeln der aktuellen Nachfrage angepasst: aus Feldgrau schafft Dividende wurde nun Das gefesselte Heer. Meine Kriegsgefangenschaft, und Zelt 27 wird niedergerissen hieß jetzt Kameraden vom Zelt 27. Deutsches Schicksal an Ruhr und Rhein. Mit diesen Titeln sowie mit Gespenster am Toten Mann wurde Ettighoffer zunächst zum Erfolgsautor, dann zum Auftragsautor und später zum Angestellten von Bertelsmann mit festem Gehalt und Gewinnbeteiligung. Nun musste er nachlegen: 1936 gelang ihm mit Verdun. Das große Gericht ein internationaler Erfolg, 1938 folgte Sturm 1918. Sieben Tage deutsches Schicksal, 1939 Tannenberg. Eine Armee wird zu Tode marschiert. Alle Bücher hatten Auflagen von weit über 100.000 Exemplaren. In diesen wenigen Jahren passte sich Ettighoffer also äußerst erfolgreich dem von der NS-Propaganda geschaffenen Markt an.

\section{Mentale AfFinitäten Zum Nationalsozialismus: SOldatische TUGENDEN, AUTORITÄRES WELTBILD UND DER TRAUM VON RUHM UND EHRE}

Will man aber Ettighoffers Wandel verstehen, von einem humanistisch geprägten Autor, der noch in Servus Kumpel seine Kritik am autoritären Obrigkeitsstaat kaum zurückhielt, zu jenem Auftragsautor bei Bertelsmann, der ein militaristisches, autoritäres und kolonialistisches Gedankengut vertrat, dann greift das Motiv der bloßen Marktanpassung und der Jagd nach Verkaufserfolgen zu kurz, obwohl es ohne Zweifel eine Rolle gespielt hat. Denn diese Anpassungsleistung an den neuen Zeitgeist war längst vorstrukturiert durch seine Wahrnehmung der Weimarer Republik als eben jene „bitteren Jahre der Zwischenzeit." Und diese Wahrnehmung wiederum wurde durch die

\footnotetext{
${ }^{14}$ Simon: Artikel „C. Bertelsmann Verlag“.

${ }^{15}$ Schneider, T. (2004: 81, Anmerkung 17).
} 
Erlebnisse geformt, die Ettighoffer als 18- bis 24-Jähriger in Krieg und Gefangenschaft gemacht hatte.

Sein Weltbild erschöpfte sich in einem ebenso geschlossenen wie wirkungs-mächtigen und jeglicher Reflexion und Kritik enthobenen soldatischen Ehrenkodex, zu dem Tugenden gehörten wie Ehre, Pflichterfüllung, Vaterlands-liebe, Treue, Opferbereitschaft, Tapferkeit, Manneszucht, Kameradschaft und Heldentum. ${ }^{16}$ Sie sind die Grundpfeiler seiner Weltorientierung. An ihnen wird der Mensch, vor allem der deutsche Mann gemessen. Politisches Räsonieren, diskutieren oder gar in-Frage-stellen und kritisieren - also Grundtugenden einer Demokratie - sind demgegenüber eindeutig negativ besetzt, da aus ihnen nur Zwietracht statt Eintracht entstehen könne. Insofern kann man von einem mit demokratischer Unreife gepaarten autoritären Weltbild sprechen. Das ist aber noch kein nationalsozialistisches Gedankengut.

Genau wie Werner Beumelburg, einer der erfolgreichsten deutschen Kriegsschriftsteller der 1920er und 1930er Jahre, der im „Bruderkampf der öffentlichen Meinung" "ein tödliches Gift" sah, das zur "Schwächung und Untergrabung der Staatsgewalt" ${ }^{\prime 17}$ führen musste, sah auch Ettighoffer die Westfront im Sommer 1918 durch Verrat an der Heimatfront geschwächt und gefährdet: erstens durch Politiker, die "ganz offen von einem Frieden der Nachgiebigkeit“18 (das heißt hier: ohne Annexionen) sprachen, zweitens durch „viele dunkle Gestalten, [...] - die Schieber, die Verräter und die Fahnenflüchtigen"19 und drittens durch "die Weichen, die Feigen und Verhetzten. ${ }^{20}$

Wie bei Beumelburg werden die vermeintlich Schuldigen (mit Ausnahme der Kommunisten) nicht konkret benannt, es wird nicht präzisiert, wer warum den unterstellten Verrat begangen hat. Im Gegenteil:

Alle Deutschen scheinen auf eine gewisse Weise ein wenig Mitschuld am inneren Zerwürfnis während des Krieges zu tragen - alle, mit Ausnahme der tapfer kämpfenden Soldaten. ${ }^{21}$

Was Krumeich hier für Beumelburg konstatiert, gilt ohne Abstriche auch für Ettighoffer.

Neben den erwähnten soldatischen Tugenden ist es dieses Verratsnarrativ, ist es die von Ludendorff und Hindenburg perfide inszenierte

\footnotetext{
${ }^{16}$ Alle diese Begriffe finden sich, vielfach wiederholt, in Sturm 1918, aber auch in den meisten anderen seiner Weltkriegsbücher.

17 Beumelburg (1929: 284).

18 Ettighoffer (1938: 267).

${ }^{19}$ Ettighoffer (1938: 321).

${ }^{20}$ Ettighoffer (1938: 311).

${ }^{21}$ Krumeich (2011: 303).
} 
,Dolchstoßlegende', um die sich die Kriegsdeutung und die Gegenwartsanalyse bei Ettighoffer drehen.

Dennoch ist die Frage nach der Schuld für die nicht überwundene Niederlage nicht das zentrale Thema Ettighoffers. Dafür ist die Benennung der Schuldigen zu unpräzise, zu peripher und punktuell eingestreut in sein Werk. Ettighoffers zentrales Schreibmotiv ist vielmehr die - in seiner Wahrnehmung - durch die Niederlage ausgebliebene Anerkennung der übermenschlichen Leistung und des Heldentums des deutschen Frontsoldaten im 1. Weltkrieg. Ebenso wie für Beumelburg kam folglich auch für Ettighoffer mit Adolf Hitler der längst überfällige Aufstieg des Frontsoldaten an die Macht, „als Erfüllung eines lange gehegten kollektiven Traums von Deutschlands Rückkehr zu Größe und Ehre. “22

Größe und Ehre sind Kategorien, die an der Schnittstelle zwischen sozial konstruierten Gefühlen und gesellschaftlich-politischen Erwartungen entstehen und konstitutiv für konservative Mentalitäten sind. Im Kern drücken sie ein emotionales Identitätsbedürfnis aus. Dass der Nationalsozialismus dieses Bedürfnis massiv ansprach und bediente, macht noch nicht alle, die es teilten, zu Nationalsozialisten, aber es erklärt eben die Empfänglichkeit für die Inszenierungen nationalistischer Emotionspolitik. Diese Empfänglichkeit lässt sich an einem so unpolitischen Autor wie Ettighoffer anhand der Werke, die er zwischen 1931 und 1937 veröffentlichte, beispielhaft analysieren.

\section{GESPENSTER AM TOTEN MANN, ODER: DiE KUNST, EINE NIEDERLAGE IN EINEN SIEG UMZUDEUTEN}

Das Buch Gespenster am Toten Mann ${ }^{23}$ erschien 1931, also mitten im Boom der Fronterlebnisbücher, der 1928 von Remarques Im Westen nichts Neues und Ludwig Renns Krieg ausgelöst wurde, und damit in einem Kontext, in dem die Authentizitätsfrage das entscheidende Kriterium für Glaubwürdigkeit war. Als glaubhaft galten vor allem eigene Fronterfahrungen. Dieser Erwartungshaltung entsprechend erzählte Ettighoffer seine Kriegserlebnisse in Form eines spannend geschriebenen Romans mit einem Ich-Erzähler, der zwischen fiktivem und autobiografischem Ich angesiedelt ist. Er folgt den realen Stationen von Ettighoffers Kriegsteilnahme und bietet eine stilisierte und angereicherte Erinnerung an die Geschehnisse.

Die Unbestimmtheit und Polysemie des titelprägenden Wortes ,Gespenster ' ist ein bewusst eingesetztes Gestaltungsmittel. Mal hat es im Roman die Bedeutung von ,aussehen wie Gespenster im Nebel', ein anderes Mal von den ,Todgeweihten' einer Schlacht. Eine dritte Bedeutung der

\footnotetext{
${ }^{22}$ Krumeich (2011: 307).

${ }^{23}$ Gilde Verlag, Köln, 1931. Zitiert wird nach der Ausgabe im Bertelsmann Verlag, Gütersloh, 1937.
} 
"Gespenster des Grauens" ${ }^{24}$ bezieht sich auf das Angesicht des Krieges, eine vierte auf die Erinnerung an erlebtes oder gesehenes Leid, eine fünfte besteht in der Todesahnung vor dem kommenden „Opfergang."

Gespenster am Toten Mann ist ohne Zweifel auch der Versuch, die Gespenster des Krieges, im Sinne der den Autor nicht loslassenden Erinnerungen an die gefallenen Kameraden, $\mathrm{zu}$ überwinden, also Erinnerungsarbeit als Versuch der Trauma-Bewältigung. Diesen Kameraden will Ettighoffer ein Erinnerungs-denkmal setzen, welches im Titel zugleich konkret verortet wird: es geht um die Westfront.

Dabei verklärt Ettighoffer, erstens, sein Westfronterlebnis zu dem Westfronterlebnis und letzteres, zweitens, zu dem Erlebnis seiner Generation schlechthin, vor dem alles Vorige klein und nichtig erscheint. Damit treibt Ettighoffer ein Verfahren auf die Spitze, das für eine Vielzahl von literarischen Texten, Im Westen nichts Neues eingeschlossen, typisch ist: „das individuelle Kriegserlebnis zu homogenisieren und auch in der Erinnerung einem größeren Ganzen oder einer Gruppe unterzuordnen." ${ }^{25}$

Gespenster am Toten Mann ist ein Paradebeispiel für eine Ästhetik des Schreckens, die Gewalterfahrungen verarbeitet und eine eingehendere Analyse verdienen würde, als dies hier möglich ist. Der sachliche, emotionslose Ton der Darstellung passt sich der Normalität des Todes an. Der Krieg wird stets als Schicksal wahr- und angenommen, einer Naturkatastrophe gleich, sinnlos, nach ihrem Sinn zu fragen.

Aber dieses Sinndefizit, diese unaufhörliche Beschreibung von Opfern, dieses ,Heldentum' der Verlierer verweist natürlich auch mit jeder Seite des Romans auf die Frage: War das alles umsonst?

Ettighoffer stellt diese Frage nicht explizit - er überlässt sie und die Antwort dem Leser. In genau diese Lücke stießen dann diejenigen, die die offene Sinnfrage (,wofür?“) in eine offene Rechnung umdeuteten, deren Begleichung in einem neuen Krieg den Opfern des 1. Weltkriegs nachträglich einen Sinn verleihen sollte.

Es wäre falsch zu behaupten, dass Ettighoffer durch diese Leerstelle in seiner Erzählung den Nazis zugearbeitet hätte. Immer wieder finden sich Szenen, die trotz aller Abstumpfung und Härte auf eine Schicht nicht zerstörbarer Menschlichkeit verweisen. In der Mitte eines bis dahin durchaus in humanistischer Tradition stehenden Buches setzt sich Ettighoffer dann aber doch von dem Gedankengut ab, dem sich Remarque verpflichtet sah, nämlich im Kontext der Dialektik von Masse und Einzelnem.

Wenn sinnloses Heldentum kein Heldentum, sondern einfach nur sinnlos ist, weil es nicht belohnt wurde - so jedenfalls konnte man Remarque

\footnotetext{
${ }^{24}$ Ettighoffer (1937a: 129).

${ }^{25}$ Vgl. Schneider T. F. (2008: 9).
} 
interpretieren ${ }^{26}-$, dann kam für die Autoren des soldatischen Nationalismus alles darauf an, trotz der Niederlage einen Sinn in diesem Heldentum zu finden, um es wenigstens als Heldentum zu retten. Und das hieß, den Sinn vom erfolgreichen Ausgang des Krieges zu entkoppeln.

Genau das versuchte Ettighoffer, wenn er darauf beharrte, dass der Sinn nicht im Sieg, sondern in der Hingabe an die Gemeinschaft bestehe:

Wer lebt heute noch von diesen Leuten? Viele deckt die Erde. Selbst ihre Namen sind schon aus unserem Gedächtnis gewischt. So schnell vergeht ein Mensch. Der Mensch ist nichts, das Ganze ist alles. ${ }^{27}$

Diese Zuspitzung ist Remarque diametral entgegengesetzt: Der Sinn des Lebens und Sterbens des Einzelnen liegt für Ettighoffer im Ganzen. Remarque hatte genau das in Frage gestellt, woran Ettighoffer festhalten will: dass der Tod des Einzelnen seinen Sinn allein in der Aufopferung für die Gesamtheit des eigenen Volkes findet, dass Heldentod folglich sinnvoll ist. Das war in Erziehung und Tradition bis dahin fast unhinterfragt gewesen. Und daran hält Ettighoffer fest. Im Zusammenhang mit seinen anderen Kriegsromanen steht fest, dass es für ihn völlig undenkbar ist, der Einzelne könne sich aussuchen, wann es sinnvoll sei zu sterben und wann nicht. Die Opferbereitschaft für die Heimat, wie es in seinen Werken immer wieder heißt, muss absolut und unhinterfragbar sein, alles andere ist für ihn Feigheit und Drückebergerei und somit eines ehrenvollen Andenkens unwürdig.

Wer sich mit soldatischen Tugenden und Anstand - Ettighoffer betont immer wieder die Ideale von Ritterlichkeit, Tapferkeit, Gleichmut und Kaltblütigkeit - für das Vaterland opfert, hat folglich umgekehrt Anspruch darauf, von diesem als Held geehrt zu werden - das gebietet das reziproke Verhältnis von Einzelnem und Ganzem. Deswegen schreibt Ettighoffer gegen das Vergessen der Toten an, ihrer Leiden, ihrer Selbstaufopferung und ihres Mutes, dessen es bedurfte, um in der immer wieder detailreich beschriebenen Hölle auszuharren. Das darf für ihn nicht vom Ausgang des Krieges abhängen!

Wenngleich diese Erinnerungsarbeit nicht völlig frei bleibt von kriegsverherrlichenden Momenten, so besteht ihr eigentlicher Sinn doch in der Mahnung an die nachfolgende Generation, durch Versöhnung und durch die Überwindung von Völkerhass den Krieg zu überwinden. Denn obwohl in seiner Sicht der Krieg eine Herausforderung für abenteuerliche Männlichkeit ist, unterm Strich bleibt er doch ein Verbrechen. Das spricht Ettighoffer sogar noch deutlicher aus als Remarque, in einer Szene, die sehr an das Motiv der verlorenen Generation bei Remarque erinnert:

\footnotetext{
${ }^{26}$ Man kann sich an dieser Stelle die, natürlich rein spekulative, Frage stellen, ob Remarque Im Westen nichts Neues jemals geschrieben hätte, wenn Deutschland den Krieg gewonnen hätte und die Überlebenden seiner Generation als Kriegshelden im Triumphmarsch heimgekehrt wären.

${ }^{27}$ Ettighoffer (1937a: 198).
} 
Weißt du, wie wir ausmarschierten, alles flotte, junge Kerle, die Bäume ausreißen wollten. [...] Es ist vielleicht gut, dass wir fallen und sterben, denn wir würden uns doch nie ins friedliche Leben schicken können. Unsere Grabkreuze werden eine Mahnung sein für die anderen, die Jungen.

Das größte Verbrechen an Deutschland, ja, an der ganzen Menschheit, ist dieser Krieg - .28

Spätestens hier wird deutlich, dass die Interpretation des Buches als AntiRemarque in den Reihen des soldatischen Nationalismus nicht haltbar ist. Vermutlich haben in der zweiten Hälfte der 30er Jahre Autoren aus der ,Mannschaft' ihren Kollegen so sehen wollen, klar ist auch, dass Ettighoffer einer solchen Interpretation auf keinen Fall entgegentreten konnte, war doch Remarque, der den Sinn des Heldentums in Frage gestellt hatte, das Feindbild der ,Mannschaft' schlechthin.

Ebenso wichtig wie die Sinnfrage war die Frage nach dem Grund der Niederlage. Lag es an der Revolution, den Kommunisten, den „Verhetzten“, wie Ettighoffer sie später meistens nannte? Nein, Ettighoffer erwähnt zwar den Streik der Munitionsarbeiter aus der Perspektive der empörten Frontsoldaten, aber der wird nicht für die Niederlage verantwortlich gemacht. Lag es an fehlender Unterstützung in der Heimat? Nein, trotz der fürchterlichen Versorgungslage wird der Durchhaltewillen der Hungernden in der Heimat als vorbildlich dargestellt: "Ihr Aushalten war groß und heldenhaft.“29 Lag es an der fehlenden Kampferfahrung und dem fehlenden Enthusiasmus der neuen Kohorten? Nein, Ettighoffer betont zwar diese beiden Aspekte an den jungen Rekruten, aber ohne jeden Vorwurf, seine Beobachtungen drücken mehr Mitleid als Anklage aus. Anklage, Wut und die ganze Verachtung des Frontsoldaten gelten nach Ettighoffer vielmehr den Drückebergern und der Etappe, aber auch sie werden nicht für den Ausgang des Krieges verantwortlich gemacht.

Für die Niederlage verantwortlich ist in Gespenster am Toten Mann die Kombination von zwei Faktoren: die eigenen Versorgungsdefizite und der Eintritt der Amerikaner in den Krieg. Als es zum ersten Gefecht mit amerikanischen Truppen kommt, heißt es im Text, das Ende vorwegnehmend: es ist „der erste Kampf, bei dem wir Sieger bleiben, aber auch erkennen, dass solche Menschenmassen und solches Material uns erdrücken werden, heute vielleicht noch nicht, aber morgen. “"

Dennoch siegen sie weiter, sie siegen bis zum Ende des Buches, bis zur Gefangennahme des Ich-Erzählers, aber dies ist zugleich der Moment, an dem sich die Niederlage deutlich abzeichnet. 65 Kilometer vor Paris ist der „Schlusspunkt unseres Vormarsches“ erreicht.

\footnotetext{
${ }^{28}$ Ettighoffer (1937a: 319).

29 Ettighoffer (1937a: 134).

30 Ettighoffer (1937a: 271).
} 
Vor uns hat sich der Widerstand gewaltig verdichtet und wir sind abgehetzt, wir können nicht mehr. [...] Jetzt rollen die Würfel unseres Schicksals abwärts, ganz rasch abwärts, denn vor uns tritt Amerika auf den Plan. ${ }^{31}$

Der sich abzeichnenden äußeren Niederlage stellt sich allerdings ein innerer Sieg gegenüber: statt dass es zu Auflösungserscheinungen kommt, nimmt die Kameradschaft sogar noch zu!

Überhaupt sind die täglichen Verluste an Offizieren sehr hoch. Das Gerippe des ganzen Widerstandes besteht überhaupt nur noch aus einigen Offizieren, aus Unteroffizieren und wenigen Stammmannschaften. Je toller es wird, desto inniger gestaltet sich jetzt die Kameradschaft. Unsere Frontoffiziere leben und sterben mit uns und für uns. ${ }^{32}$

So gelingt Ettighoffer am Ende die Kunst, eine militärische Niederlage in einen moralischen Sieg umzudeuten. In einen Sieg des Heldentums der deutschen Frontkämpfer, das unter den ausführlich geschilderten Leiden ein Höchstmaß erreichte, und denen hier die gebührende Ehre erwiesen werden soll, insbesondere den Elsässern unter ihnen, auch wenn der Sieg nicht erreicht wurde.

Am deutschen Frontsoldaten, das soll jedem Leser am Ende des Buches einleuchten, hat es nicht gelegen, dass der Krieg verloren wurde, denn er hat bis zum Schluss alles Menschenmögliche gegeben. Am Ende lag es einfach an der Übermacht von Menschen und Material beim Gegner, vor allem seit dem Kriegseintritt der Amerikaner.

Damit bedient diese Darstellung nicht das Verratsnarrativ, unterstützt nicht die These vom Dolchstoß, und angesichts der ausführlich beschriebenen Aufopferung der Heimat auch nicht die These Hitlers, der Krieg sei an der Heimatfront verloren worden. Gespenster am Toten Mann hat sehr viele Schnittmengen mit dem soldatischen Nationalismus gemeinsam, vor allem die Heldenverehrung, mit dem Nationalsozialismus dagegen keine. Es ist ein durchaus eigenständiges Buch im Kontext der Fronterlebnisromane, vermutlich das beste Ettighoffers.

Es stellt sich also die Frage, warum Ettighoffer diese Sicht, die noch im Einklang steht mit Jüngers In Stahlgewittern und auch mit Remarques Bestseller, später aufgibt und sich das Verratsnarrativ zu eigen macht.

\section{VERGLEICH MIT VERDUN - DAS GROßE GERICHT}

Auch in dem 1936 zum 20. Jahrestag der Schlacht erschienenen Kriegsbuch Verdun. Das große Gericht ${ }^{33}$ ist nichts von der Dolchstoßlegende $\mathrm{zu}$ finden.

\footnotetext{
${ }^{31}$ Ettighoffer (1937a: 315).

${ }^{32}$ Ettighoffer (1937a: 317). Ettighoffer ist zu diesem Zeitpunkt Leutnant und setzt sich hier also auch selbst ein Denkmal.

${ }^{33}$ Gütersloh, Bertelsmann, 1936.
} 
Allerdings geht es hier auch nicht um den Ausgang des Krieges, sondern um eine einzelne Schlacht, die aber nicht ohne Auswirkungen auf das Kriegsgeschehen an der Westfront insgesamt war.

Immer wieder betont Ettighoffer durch eine im Vergleich zu Gespenster am Toten Mann noch einmal deutlich detailreichere Schilderung des Grauens und Leidens, worauf es ihm eigentlich ankommt: der deutsche Feldgraue hat alles erduldet was denkbar und gegeben was möglich war, aber viele seiner Opfer waren sinnlos und von der Obersten Heeresleitung (OHL) auch so geplant gewesen.

Stellt man die im Buch verteilten entsprechenden Passagen zusammen, dann ergibt sich eine sehr deutliche Kritik an der militärischen Führung, die bei der Lektüre des Buches so nicht direkt ins Auge springt.

Das beginnt mit der Formulierung vom "sinnlosen Abschlachten“, wie es "nie zuvor ein menschliches Hirn [...] ersann, " ${ }^{44}$ und zwar nach „Falkenhayns Plan.“" ${ }^{35}$ Dann heißt es: „Die Ausblutungsschlacht hat zwar planmäßig [...] eingesetzt, aber auch bei der deutschen Truppe. ${ }^{\text {36 }} \mathrm{Zu}$ ihr gehört der "Opfergang der Zwanzigjährigen“: „Stumm, ohne begriffen zu haben, fallen sie. Ihr Opfer ist groß, aber nutzlos. ${ }^{\prime \prime 37}$

,Nutzlose' Opfer gelten gemeinhin als Führungsversagen. Aber solche Schlüsse muss jeder Leser selbst ziehen. Dennoch nähert sich die Schilderung von Tatsachen zunehmend einer Anklage: „in diese von Unmenschlichkeit ersonnene Menschenmühle, wirft ein Federstrich diesen Jahrgang 1896. Hier fallen sie in Massen. ${ }^{\text {38 }}$

Die Kritik bezieht sich auf viele Ebenen der Kampfplanung und verbindet schließlich sogar, wenngleich wieder nur indirekt, die Verantwortung der militärischen Führung für den Ausgang der Schlacht mit derjenigen für den Ausgang des Krieges insgesamt. Verdun, so der Autor, hätte eingenommen werden können, wenn die Ausblutungsstrategie Falkenhayns den Vorwärtsdrang der Frontsoldaten nicht mehrfach gebremst und später die Verlegung von Artillerie und Truppen an die Somme die Infanterie vor Verdun nicht beim Zugriff auf die Stadt im Stich gelassen hätte.

Insgesamt dominiert in dem Buch aber der Vorwurf sinnlosen Sterbens: "Jedes Opfer wirkt wie ein Schlag ins Wasser, wenn es seinen Sinn verliert.“ ${ }^{39}$ Fast klingt es wie bei Remarque.

${ }^{34}$ Zitiert wird, wenn nicht anders angegeben, nach der Neuausgabe, Augsburg, 2000, hier: 107.

${ }^{35}$ Ettighoffer (2000: 19).

36 Ettighoffer (2000: 111). Ob es tatsächlich eine "Ausblutungsschlacht" war, wird von Historikern in Frage gestellt, so etwa von Gerd Krumeich (2015).

${ }^{37}$ Ettighoffer (2000: 112f.).

38 Ettighoffer (2000: 114).

${ }^{39}$ Ettighoffer (2000: 278). 
Verdun - Das große Gericht ist eine Anklage gegen sinnloses Massensterben. In der Nachkriegsausgabe ${ }^{40}$ wird diese Anklage im Sinne einer Völkerverständigung und Neubewertung des „heldenhaften“ Sterbens durch verschiedene Änderungen und Zusätze noch akzentuiert. ${ }^{41}$

Worauf es Ettighoffer 1936 ankam, war, vom „tapferen Kämpfen“ von „zwei große[n] Nationen und ihre[n] besten Soldaten“ zu erzählen, „und auch von ihrem stillen Heldentum und ihrem einsamen Sterben." 421975 klang das so: „Ihr Leiden und Sterben soll zum Völkerfrieden mahnen [...] für das es kein Vergessen geben darf. “43

Auch wenn einige Änderungen in der Neuausgabe erkennen lassen, dass Ettighoffer sich erst sehr spät zu manchen Einsichten durchringen konnte, darf nicht verschwiegen werden, dass schon auf dem Einband der 1936-Ausgabe ein deutscher und ein französischer Helm zu sehen sind, die von zwei Lorbeerzweigen eingefasst werden - ein Symbol, das Ettighoffers Respekt vor dem Gegner bekundet und in diametralem Gegensatz zu Hitlers späterer Kriegsführung im Osten steht. Dass dieses Detail im dritten Jahr der NS-Herrschaft überhaupt noch möglich war, lässt sich nur dadurch erklären, dass die NS-Propaganda Mitte der dreißiger Jahre, und ganz besonders 1936, im Jahr der Olympischen Spiele in Berlin, sehr darum bemüht war, im Ausland als friedliebend wahrgenommen $\mathrm{zu}$ werden und das Vertrauen gerade auch der

40 Vermutlich hat Ettighoffer sie 1963 oder bald danach bearbeitet. Darauf deutet die Erwähnung (auf S. 312) eines Treffens in Verdun unter dem Leitspruch „Versöhnung über Gräbern" aus diesem Jahr hin. Das Buch erschien ohne Angabe des Jahres im Bechtermünz Verlag wahrscheinlich 1976, mit einem Nachwort von Maurice Genevoix, in dem er auf den offenbar unmittelbar zurückliegenden Tod des Autors im Jahr 1975 Bezug nimmt. Im Jahr 2000 hat der Weltbild Verlag in Augsburg eine genehmigte Lizenzausgabe herausgebracht, ein Nachdruck der Bechtermünz-Ausgabe, auf den hier Bezug genommen wird.

${ }^{41}$ Beispielsweise lautet ein Passus, der erst in der Nachkriegs-Ausgabe eingeschoben wurde, wie folgt: "Aber es ist nicht das Heldentum, das diese Kämpfer in früheren Geschichtsbüchern lasen, das Heldentum, das ihnen als Vorbild in der Schule geschildert wurde, das Heldentum des Sterbens im weiten und breiten Feld als ,schönsten Mannestod'. Hier haben sie erkannt, daß kein Tod schön sein kann. Hier [...] hat der Verdunkämpfer hüben und drüben den Wert eines Menschenlebens erkannt. So seltsam es klingen mag, je länger die Qual der Verdunschlacht dauerte, je rasender das Feuer tobt, desto geringer wird jedes Gefühl der Feindschaft. Man bedauert den Gegner [...].

Man achtet sich gegenseitig. [...] Zwischen ihnen herrscht kein Haß, sondern kameradschaftliches Verständnis wie zwischen Männern, die alle dasselbe furchtbare Schicksal zu tragen haben!

Und dies ist ihr Heldentum, das ihnen niemals geschmälert werden soll; sie haben ihre harte Pflicht erfüllt. Erfüllt, wie das Vaterland dies forderte. Aber Haß! Nein, Haß haben sie nie gekannt. Im Trichterfeld um Verdun, angesichts des Todes [...] war kein Platz mehr für kleinlichen Haß“ (Ettighoffer 2000: 121f.).

42 Ettighoffer (1936: 7).

${ }^{43}$ Ettighoffer (2000: 11). 
französischen Kriegsveteranen zu erlangen, nachdem im Jahr zuvor die Aufrüstung der Wehrmacht begonnen hatte. ${ }^{44}$

\section{Vergleich Mit StURM 1918. Sieben TAge DeUTSCHES SCHICKSAL}

Die Bertelsmann-Ausgabe ${ }^{45}$ dieses Buches zur 20. Wiederkehr des letzten Kriegsjahres ist 321 Seiten lang zuzüglich eines halbseitigen Nachwortes und eines Verzeichnisses benutzter Quellen, die Hälfte davon auf Deutsch, die andere auf Französisch. Von den sieben Tagen des Untertitels, ${ }^{46}$ die den Aufbau des Buches strukturieren, geht es für die deutschen Armeen fünf Tage vorwärts, sie eilen quasi von Sieg zu Sieg, stehen gut einen Tagesmarsch vor Paris, bis am sechsten Tag, dem 18.7.1918, der französische Gegenstoß beginnt. Das geschieht im Buch auf Seite 296. Das heißt, ca. 7,8 \% des Buches behandeln die deutsche Niederlage, über $90 \%$ dagegen deutsche Erfolge, sodass sich der zeitgenössische deutsche Leser, der den Ausgang des Krieges ja kannte, fragen musste: Was konnte da denn noch schief gehen? Warum haben wir uns den Sieg aus den Händen nehmen lassen?

Noch auf Seite 252 heißt es: „Die französische Artillerie [...] kann sich kaum noch wehren. Das Ende scheint nahe." Und Pétain sah laut Ettighoffer die Umzingelung von Paris „unausbleiblich, wenn nicht ein Wunder geschieht, ein zweites Marnewunder!“"47

Damit wird es diesmal unausweichlich, die Frage nach dem Grund für die Niederlage zu stellen.

Eines ist erneut klar: an den deutschen Frontsoldaten hat es nicht gelegen - das versucht der Text von der ersten bis zur letzten Seite zu beweisen. Immer wieder seien sie in ihrem unermüdlichen, heldenhaften Vorwärts-Drang behindert oder alleine gelassen worden - dasselbe Argumentationsschema, das schon Ettighoffers Verdun-Buch dominierte. Oft hätten sie mehr erreicht, als die OHL von ihnen erwartet bzw. überhaupt für möglich gehalten hätte.

Im Unterschied zum Verdun-Buch wird dieses Mal aber nicht die Generalität oder OHL verantwortlich gemacht; insbesondere Ludendorff wird von der Kritik ausgenommen. Nein, am Ende geht es sehr schnell mit den

${ }^{44}$ Vgl. Moreau-Trichet (2002).

${ }^{45}$ Gütersloh (1938).

46 1. Tag: 21.3.2018, Beginn der „Kaiserschlacht“.

2. Tag: 9.4.1918, ,Schlacht am Kemmel-Berg“.

3. Tag: 27.5.1918, „Husarenstreich der deutschen Armee“ (rascher Vormarsch zwischen Noyon, Soissons, dem Chemin des Dames, Fisnes und Reims).

4. Tag: 9.6.1918, Vorstoß zwischen Noyon und Montdidier.

5. Tag: 15.7.1918, Vorstoß rechts und links von Reims.

6. Tag: 18.7. 1918, Foch greift an.

7. Tag: 8. 8. 1918, Der schwarze Tag des deutschen Frontheeres.

${ }^{47}$ Ettighoffer (1938: 254). 
Erklärungen: die Spanische Grippe, die schlechte Versorgungslage Deutschlands bezüglich Ernährung, Waffen und Munition und der Zeitdruck, den Krieg gewinnen zu müssen, bevor die Amerikaner wirkungsvoll eingreifen konnten. Ferner verhinderte Verrat bzw. mangelnde Geheimhaltung einen Erfolg des letzten Großangriffs.

Als ob hiermit nicht bereits das Wesentliche erklärt wäre, kommt, wie aus dem Nichts, auf der allerletzten Seite, als Finale furioso sozusagen, die Dolchstoßlegende ins Spiel.

Bei genauerem Hinsehen wird dieser überraschende Schlusspunkt allerdings sorgfältig vorbereitet. Denn trotz aller feindlichen Übermacht, trotz Hunger und Ermüdung, trotz fehlender Munition hält der deutsche Soldat ${ }^{48}$ die Stellung: „Nirgendwo gelingt den Alliierten der ersehnte Durchbruch. Die deutsche Front hält immer noch und kämpft. " ${ }^{49}$ Das ist der Anknüpfungspunkt für den Mythos: Im Felde unbesiegt. Nachdem das klargestellt wurde, erscheint auf der letzten Seite des Buches ganz plötzlich ein „Gespenst“:

\footnotetext{
Und währenddessen wächst am östlichen Horizont ein schreckerregendes Gespenst. Wie ein ungeschlachter Riese steht es da. Seine Lippen geifern Blut. [...]

,Revolution' heißt der brutale Riese!

Hinter ihm drängen sich viele dunkle Gestalten, $[\ldots]$ - die Schieber, die Verräter und die Fahnenflüchtigen. [...]

Und der Riese hebt den Dolch, lässt ihn sekundenlang aufblitzen in der müden herbstlichen Abendsonne und stößt ihn dem tapferen Feldgrauen in den Rücken. ${ }^{50}$
}

In unmittelbarer Fortführung und Zusammenfassung dieser beiden Mythen - unbesiegt im Feld erleidet das deutsche Heer den Dolchstoß in den Rücken - schließen daran die beiden letzten Sätze des Buches an, die die Perspektiven bündeln und die Interpretation der deutschen Niederlage auf den Punkt bringen: „Gesicht zum Feind, kämpfend bis zum letzten Atemzug, stirbt das unbesiegte deutsche Frontheer, den Dolch schmachvollen Verrats im Nacken..." ${ }^{\text {51 }}$

Hier werden Tatsachen verdreht und beiseite gewischt, hier wird ein Mord erfunden und es wird suggeriert, dass die Niederlage vermeidbar gewesen sei, hier geht es nicht mehr um die historische Wahrheit, sondern darum, die Ehre des deutschen Frontsoldaten zu retten. Das alles wird in einem einzigen, eingängigen Bild zusammengefasst und beschworen, für welches im deutschen kollektiven Gedächtnis bereits ein Anschlussmythos existierte, an den dieses Bild nahtlos andocken konnte und der es an seiner Aura von ewiger

${ }^{48}$ Durch eine stilistisch sehr gezielt eingesetzte Wiederholung dieser Formulierung wird hier der deutsche Soldat bewusst stereotypisiert und als solcher per se von aller Schuld freigesprochen. Vergessen sind die vormaligen Differenzierungen zwischen Front und Etappe, hier geht es pauschal um das gesamte Feldheer.

49 Ettighoffer (1938: 320).

50 Ettighoffer (1938: 321).

${ }^{51}$ Ettighoffer (1938: 321). 
Heldentragik und damit an seinem poetischen Wahrheitsgehalt teilhaben lässt: es ist die Stelle aus dem Nibelungenlied, in der Hagen hinterhältig dem ebenso arg- wie furchtlosen Helden Siegfried die Lanze in den Rücken sticht. Dieses Bild, das jeder Deutsche kannte, hatte dank seiner Eingängigkeit eine unmittelbare Überzeugungskraft, die es aller kritischen Hinterfragung enthob.

Hier schimmert eine lange anhaltende Mentalität damaliger deutscher Offiziere durch, die beim Infanterieleutnant Ettighoffer beginnt und bis in die OHL hinaufreicht: sie sind Willensmenschen statt Realisten. „In kollektiver Wirklichkeitsverdrängung“ verweigerte die deutsche Militärelite die Anerkennung der „realen strategischen Ursachen für die Niederlage - nämlich die Unterlegenheit der deutschen Kräfte.“52 Diese Erkenntnis wurde „bewusst oder unbewusst verdrängt." ${ }^{53}$ Die auf eine extreme Willensanstrengung und eine „Opferbereitschaft“, wie sie laut Ettighoffer „,noch nie ein Volk im Wandel der Geschichte gezeigt hat, "54 folgende niederschmetternde Enttäuschung über die Niederlage versperrte offenbar auch weiten Bevölkerungskreisen noch im Nachhinein eine realistische Einschätzung der wahren Gründe für die Niederlage: „Dies konnte für viele Deutsche nicht mit rechten Dingen zugegangen sein. Verrat wurde zum geflügelten Wort. “"

\section{DAS VERRATSNARRATIV}

„Kein Feind hat euch überwunden!“ rief Friedrich Ebert am 10. Dezember 1918 den heimkehrenden Truppen in Berlin zu. Eine Woche später veröffentlichte die Neue Zürcher Zeitung eine anonyme Zusammenfassung zweier Artikel des englischen Generals Sir Frederick Maurice, die in die Behauptung mündete, die deutsche Armee sei „von der Zivilbevölkerung von hinten erdolcht“ worden, was den „irrigen Eindruck“ erweckte, nicht der Journalist sondern der britische General habe diese Worte geäußert. ${ }^{56}$ Diese Annahme, dass selbst ein hochrangiger Kriegsgegner sich die deutsche Niederlage nicht anders als durch einen Verrat der Heimat an der Front erklären konnte, wurde in der konservativen Presse derart ausgeschlachtet, dass schon im Juni 1919, während der Pariser Friedensverhandlungen, die linksintellektuelle Weltbühne genug hatte von dem "Geplärr" vom „unbesiegten Heer, das hinterrücks erdolcht wurde. ${ }^{\circ 57}$

Noch vor der Unterzeichnung des Versailler Vertrags standen sich somit zwei diametral entgegengesetzte Auffassungen über die Gründe für die

\footnotetext{
52 Groß (2018: 144).

${ }^{53}$ Groß (2018: 134).

54 Ettighoffer (1938: 206).

55 Groß (2018: 134).

56 Groß (2018: 128f.). Maurice bestritt vehement und wiederholt, eine solche Aussage gemacht zu haben.

${ }^{57}$ Die Weltbühne, Band 15/I, 1919, Heft 6.
} 
deutsche Niederlage gegenüber: einerseits auf national-konservativer Seite das Verratsnarrativ, das der Heimat und der Revolution die Schuld an der Niederlage gab und andererseits auf der politischen Linken die Demaskierung dieser Erklärung als absurde Tatsachenverdrehung und niederträchtiger Versuch, den politischen Gegner für das eigene Versagen verantwortlich zu machen.

Am 18. Dezember 1919 gab dann Hindenburg vor dem Untersuchungsausschuss der Nationalversammlung zu Protokoll, nicht die politische und schon gar nicht die militärische Führung des Kaiserreichs seien für die Niederlage verantwortlich gewesen, sondern die Heimat sei dem „im Felde unbesiegten" Heer in den Rücken gefallen und habe es von hinten erdolcht. 1920 schmückte er diese Version in der Publikation Aus meinem Leben noch mit dem Bild vom "grimmigen Hagen" und seinem "hinterlistig[en]" Speerwurf in Siegfrieds Rücken literarisch wirkungsvoll aus. ${ }^{58}$

In den folgenden Jahren gab es Prozesse, Gutachten und einen förmlichen Pressekrieg über die Frage nach der Schuld an der Niederlage. Zusätzlich wirkten die harten Friedensbedingungen des Versailler Vertrages wie Salz in einer offenen Wunde, die die Legitimität der Weimarer Republik von Anfang an in Frage stellte und mit zu ihrem Untergang führte. Da sich die Republik der Revolution vom November 1918 verdankte, wurden die Revolutionäre und ,Väter' der Republik von den Nationalsozialisten bald mit dem Kampfbegriff ,Novemberverbrecher` bezeichnet, später war dann die Rede vom ,Dolchstoß der Juden und Marxisten'.

Bereits in Mein Kampf hatte Hitler als ,Lehre' aus der Niederlage die grundsätzliche Überzeugung entwickelt, nie wieder dürften eine ideologisch mangelhaft mobilisierte Heimat und ein sozialistischer Dolchstoß der kämpfenden Truppe in den Rücken fallen.

Die verheerenden Konsequenzen der Dolchstoß-Legende und der Versuch ihrer Widerlegung haben folglich die Perspektive der Geschichtsschreibung in der Bundesrepublik Deutschland stark beeinflusst. Das hat im Endeffekt aber auch zu einem völligen Unverständnis geführt, wie denn überhaupt derart breite Bevölkerungsschichten auf etwas ,hereinfallen' konnten, was im Nachhinein als unsinnig und böswillig erscheint. Da Hitler sich seit Mein Kampf die Verratsinterpretation als Achse seiner Weltsicht zu eigen gemacht hatte, stand jeder, der an dieses Narrativ glaubte, nun seinerseits unter NS-Verdacht.

Vor diesem Hintergrund muss der Versuch Gerd Krumeichs gesehen werden, das Zustandekommen des Verratsnarrativs etwas plausibler zu machen, als es der gängigen Forschungstradition entspricht. ${ }^{59}$ Dabei geht es im Kern um die Frage, wie lange die deutsche Front noch hätte halten können,

\footnotetext{
${ }^{58}$ Vielsagend auch, dass nicht der Vorname die Titelseite des Buches schmückt, sondern der militärische Rang: Generalfeldmarschall von Hindenburg (1920: 403).

${ }^{59}$ Vgl. das Kapitel: „Dolchstoß: Lüge, Legende oder doch ein wenig wahr?“ in: Krumeich (2018: 183-209).
} 
wenn nicht die Revolution im November die Kapitulation erzwungen hätte. An diese Frage knüpft sich nämlich die Spekulation an, wie es mit der Kampfmoral der Alliierten stand und ob sie tatsächlich den Krieg noch lange hätten weiterführen, bis Berlin hätten durchmarschieren und Deutschland besetzen können, wenn Deutschland gleichzeitig Friedensverhandlungen angeboten hätte. Mit dieser Spekulation stand die These im Raum, dass man im Falle des Weiterkämpfens einen bedeutend vorteilhafteren und ,ehrenvolleren' Frieden hätte erreichen können und die Revolution tatsächlich für die Kapitulation und damit für den Versailler Frieden verantwortlich sei. Kurz: das ,unbesiegte deutsche Heer sei, wie das russische, von den Revolution verraten worden.

Militärisch gesehen war ein Sieg im Herbst 1918 nicht mehr möglich, eine Niederlage absehbar - eine Kapitulation allerdings noch nicht zwingend nötig! In der Folge wurde bewusst die Verantwortung für die Niederlage, die beim Militär lag, mit der Verantwortung für die Auflösung der Front und die Kapitulation, die bei den Revolutionären lag, vertauscht, um daraus politisches Kapital zu schlagen.

Nimmt man die fortdauernde Irreführung der deutschen Öffentlichkeit - bis hinauf in die eigene Führungsspitze! - hinzu, in deren Wahrnehmung der Sieg noch im Herbst 1918 nur eine Frage der Zeit war, dann lässt sich nachvollziehen, warum der Waffenstillstand alle sprachlos machte und Verrat das Erste war, was sich in den Köpfen all jener festsetzte, die nicht unmittelbar von der Revolution profitierten. Die politische Polarität, mit der um das Verratsnarrativ gestritten wurde, und ihre undifferenzierte, binäre Polemik - Verrat, ja oder nein? - legen auch nahe, dass Leute, die politisch eher rechts standen, sich früher oder später von der Verratspropaganda überzeugen ließen, ohne deswegen etwas mit dem Nationalsozialismus zu tun zu haben. Die Frage ist also weniger, warum Ettighoffer sich diese Perspektive schließlich doch zu eigen machte, sondern warum erst so spät und wann eigentlich genau.

\section{ETTIGHOFFER AUF REMILITARISIERUNGSKURS}

In Gespenster am Toten Mann und in seinem Verdun-Buch hatte sich Ettighoffer der Frage noch entzogen, warum der Krieg verloren ging und sich stattdessen auf seinen eigentlichen Kompetenzbereich beschränkt, nämlich die persönliche Kenntnis des Fronterlebens, des soldatischen Ehr- und Pflichtkodexes und der Psyche des Frontsoldaten. Erst in Sturm 1918 übernahm er als unpolitischer Autor ein politisches Narrativ und ging von der Darstellung des Kriegserlebnisses zu der politischen Instrumentalisierung der Kriegserinnerung über.

In dem kurzen Nachwort zu Sturm 1918 stellt Ettighoffer die Wehrmacht in eine direkte Nachfolgerschaft des deutschen Frontheeres von 1918. Dabei wird diese Kontinuität als eine Wiedergeburt „aus dem Blute, das Frankreichs Erde trank“ zwar betont vage gehalten, man geht aber wohl nicht zu weit, 
wenn man daraus eine Verpflichtung und einen Auftrag zur Revision der Niederlage von 1918 herauslesen möchte: "Sie sind nicht tot, die Männer der hundert Schlachten, sie leben wieder im deutschen Heer von 1938." 60

Hier macht Ettighoffer sich zum Propagandisten des Regimes, indem er die seit Anfang der Dreißigerjahre konstruierte Kontinuität zwischen den (alten) Weltkriegsveteranen und der (jungen) ,Bewegung', die mit Hitler an die Macht gekommen war, übernimmt. Dieses Narrativ war in den Anthologien der ,Mannschaft' konstruiert und bereits ein Jahr zuvor von Ettighoffer ganz explizit übernommen worden. 1937 hatte er nämlich im W. Crüwell Verlag das Büchlein Die Infanterie marschiert. Bilder aus dem Leben, Kämpfen und Sterben der deutschen Infanterie publiziert. Es handelt sich um eine 56 Seiten lange Werbeschrift für die Infanterie, eine Art ,geistiger Mobilmachung', geschrieben „von einem, der zu Kriegsbeginn, mit 18 Jahren, Infanterist wurde und heute noch, mit schon grauen Schläfen, innerlich immer noch Infanterist geblieben ist."61 Bereits hier wurde die Wehrmacht in eine direkte Nachfolge zu den Gefallenen des 1. Weltkrieges gestellt:

Und wenn $\mathrm{du}$ in den Reihen der Infanterie marschierst, dann ziehen neben dir, unsichtbar, die hunderttausende deutscher Infanteristen, die fürs Vaterland starben. [...] Du wirst in guter Kameradschaft marschieren, deutscher Junge! ${ }^{62}$

\section{0. ,DIE MANNSCHAFT` UND DIE KONSTRUKTION EINER KONTINUITÄT VON KRIEGSVETERANEN, NS-BEWEGUNG UND WEHRMACHT}

Zwischen 1936 und 1939 erschienen sechs Frontschriftsteller-Anthologien, davon vier Bände unter dem Titel „Die Mannschaft - Frontsoldaten erzählen vom Front-Alltag“ (Berlin/Dresden 1936-38). Diese vier Bände erschienen dann noch einmal in einer Sonderausgabe der NSKOV, ${ }^{63}$ die die Bände 1 und 2 und die Bände 3 und 4 jeweils in einem Band zusammenfasste. ${ }^{64}$

Der erste Doppelband der NSKOV vermerkt: „Copyright 1936 by Wilhelm Limpert Verlag, Berlin." Das Vorwort zu dieser Ausgabe stammt aber vom 1. August 1937. Diese Angaben gelten für beide Bände, die in diesem Sonderausgabenband zusammengefasst sind. In der Einleitung wird berichtet, dass die Idee zu diesem Projekt im Frühsommer 1935 entstand. Man darf daraus schließen, dass der ursprünglich erste Einzelband 1936 erschien. Die Frage ist, wann der ursprünglich zweite Einzelband erschien, in dem sich der

${ }^{60}$ Ettighoffer (1938: 322).

${ }^{61}$ Ettighoffer (1937b: 3).

62 Ettighoffer (1937b: 56).

${ }^{63}$ NSKOV ist die Abkürzung für Nationalsozialistische Kriegsopferversorgung.

64 Ferner erschienen 1937 „Frontsoldaten wollen den Frieden“ und vermutlich 1938 „Frontsoldaten berichten,“ sowie eine Broschüre über das „Erste Reichs-Frontdichter-Treffen der "Mannschaft' in ihrer Stadt Guben, hg. von der "Mannschaft', Kameradschaft der Frontdichter in der NSKOV, Berlin 1938. 
Beitrag von Ettighoffer befindet. Da sich die Copyright-Angabe von 1936 auch auf diesen Band bezieht, müsste also auch der ursprünglich zweite Einzelband noch 1936 erschienen sein. Die Einleitung zu letzterem gibt aber als Entstehungsgrund die positiven Rückmeldungen „in Besprechungen und Briefen" an, so dass sicherlich einige Monate vergingen, bevor sich Herausgeber und Verlag entschlossen, einen zweiten Band nachzulegen. Da es sich um eigens für diesen Band neu verfasste Texte handeln sollte, muss man einige Monate für die Kontaktaufnahme zu den Autoren, die Produktion der Texte und die Herausgabe des Buches veranschlagen, so dass der ursprünglich zweite Einzelband wohl nicht vor Winter/Frühling 1937 erscheinen konnte, was wiederum darauf hindeutet, dass Ettighoffer seinen Text in der zweiten Jahreshälfte 1936 verfasst haben dürfte und zwar in Kenntnis des ersten Bandes.

Dieser Text ${ }^{65}$ ist völlig unverfänglich und frei von NS-Gedankengut. Er begnügt sich, wie so oft, mit Heldengedenken und bringt einmal mehr Ettighoffers ganz persönliches Anliegen zum Ausdruck: das Gedenken an die elsässischen Frontsoldaten im 1. Weltkrieg, die, so führt der Text aus, weder auf französischer Seite geehrt werden, weil sie ja auf deutscher Seite kämpften, noch auf deutscher Seite in Gedenkveranstaltungen einbezogen werden, da das Elsass ja mittlerweile zu Frankreich gehörte.

Generell wollte der ursprünglich erste Band nicht an die „FrontKampftage,“ sondern an den „Front-Alltag“ erinnern, er sollte einem „,anderen Erinnern“ gewidmet sein, das, nicht kriegstreiberisch —es war das Jahr der Olympiade in Berlin! - aber doch in militärischen Geist verfasst war. In diesem "schriftstellerischen Kampfe“ wolle er „ein Bollwerk" errichten "gegen die volksverdummende Frontentheiligung eines Remarque und seiner Genossen im Ungeiste." 66

Halten wir noch einmal fest: weder in seinem Beitrag für „Die Mannschaft" von (vermutlich) 1936, noch in seinem im selben Jahr erschienenen Verdun-Buch übernahm Ettighoffer das Verratsnarrativ oder irgendwelche ideologischen Elemente der NS-Ideologie. Er blieb ein typischer Repräsentant des soldatischen Nationalismus. In seiner Broschüre Infanterie marschiert von 1937 und seinem Buch Sturm 1918 von 1938 war Ettighoffer dagegen bereits auf den Kurs deutlichen Führerlobs, auf das Verratsnarrativ und auf die Kontinuität von Veteranen und NS-Bewegung eingeschwenkt. Zwischen 1936 und 1937 kippte also seine Haltung. Und er vollzog hier etwas mit, was sich par excellence an den Anthologien der Mannschaft ablesen lässt und von Nicolas Beaupré ${ }^{67}$ in aller Deutlichkeit herausgearbeitet wurde: die Gleichschaltung der Frontschriftsteller mit der Ns-Bewegung.

\footnotetext{
65 „Vizefeldwebel Linksheraus“, im 2. Einzelband, 55-69.

66 Einleitung von Jürgen Hahn-Butry zum ursprünglich 1. Band, in der NSKOV-Sonderausgabe, Berlin 1936, 9 f.

${ }^{67}$ Beaupré (2010).
} 
Dieser Vorgang versteht sich keineswegs von selbst, denn das Leiden und Grauen der Frontsoldaten, an das Ettighoffer in seinen Kriegsbüchern unentwegt erinnerte, hatte wenig bis nichts zu tun mit dem Kampf der SA gegen die Weimarer Republik. Genau diese Kontinuität wird aber mit viel Gedankenakrobatik in den Einleitungen zu den vier Anthologie-Bänden der Mannschaft konstruiert und es wäre durchaus verständlich gewesen, wenn sich alte Frontveteranen wie Ettighoffer gegen eine solche Gleichstellung empört und verwahrt hätten.

Kurz gesagt läuft die Argumentation geschickterweise darauf hinaus, den Begriff der "Mannschaft" so weit zu fassen, dass er nicht nur die "alte Mannschaft" von "schriftstellernden Kameraden der Front" einbezieht, sondern als „Kameradschaft von Männern“ über die Veteranen hinaus anwendbar wird. ${ }^{68}$ Als Paradebeispiel für die nationale Aufgabe, nicht bloß sentimental in der Vergangenheit zu verharren, sondern diese mit der Gegenwart und Zukunft zu verbinden und zu versöhnen, gilt Hitler selbst:

Einer aus der alten Mannschaft [sic!], der Führer Adolf Hitler, war es, der seinen Mitkämpfern mit dem Begriff des ,Frontsozialismus' den alten Begriff der ,Mannschaft' erneuert wiedergab. - Aus ihr entstand das neue Reich, in dem der Front wieder die Ehre wurde, die die Novemberrepublik ihr versagte. ${ }^{69}$

Man braucht nicht viel Fantasie, um sich die Urszene der ,Mannschaft' so oder so ähnlich vorzustellen, wie sie in der Einleitung zum ersten Einzelband geschildert wird, als an einem Frühsommertag des Jahres 1935 im Kreise schriftstellernder Veteranen Otto Paust vorgeschlagen haben soll:

Kinder, eigentlich sind wir doch noch immer die alte Mannschaft, wenn auch der eine dies Buch schreibt und der andere ein anderes ... Warum schreiben wir da nicht einmal eins zusammen! 70

So unverfänglich das auch klingen mag, es wird sofort klar, dass es hier um mehr geht als um ein gemeinschaftliches Veteranen-Gedenken an den Großen Krieg, wenn man weiß, dass Otto Paust nicht nur Weltkriegsteilnehmer und Freikorpsmitglied war, sondern sich auch am Kapp-Putsch beteiligte, 1930 in die NSDAP und SA eintrat und Schriftleiter des NSDAP-Organs Der Angriff wurde. Auch der Herausgeber des 1. Einzelbandes, Jürgen Hahn-Butry, schrieb seit 1931 für den Angriff. Und dieser NSDAP-Linie entsprechend suchte man sich auch die Autoren für das geplante Projekt aus: von den 24 Beiträgern gehörten 13 der NSDAP an oder standen ihr nahe. ${ }^{71}$

\footnotetext{
68 Einleitung zum 1. Einzelband, 8.

${ }^{69}$ Ebda., 8f.

70 Ebda., 8.

${ }^{71}$ Insgesamt, auf alle Bände verteilt, kommt Beaupré zu dem Ergebnis, „dass mindestens ein Viertel der Autoren der NSDAP angehörten und dass etwa einer von zehn aus den Reihen der SA kam" (2010: 118f.).
} 
Auch, wenn die Kontinuitätsthese erst in den folgenden Bänden in den Vordergrund tritt, wusste Ettighoffer nach Kenntnis des ersten Bandes doch, worauf er sich da einließ. Es passt zu diesem politisch wenig beschlagenen Schriftsteller, dass er nicht vorausgesehen hat, dass die Kontinuitätsthese den Veteranen nur schaden konnte. Denn durch sie

verlor die Vereinigung ihren Alleinvertretungsanspruch und zugleich auch in gewisser Weise ihre Daseinsberechtigung. Von 1938 an durfte sich tatsächlich jeder nationalsozialistische Schriftsteller legitimiert fühlen, sein ,Kampferlebnis' aus der ,Kampfzeit der Bewegung' in einem Atemzug mit dem Fronterlebnis des Ersten Weltkriegs zu nennen.72

Warum sich Ettighoffer Ende 1936 überreden ließ, an diesem Projekt mitzuarbeiten, ist im Detail nicht mehr zu rekonstruieren. Auch bei anderen Autoren liegt diese Teilnahme nicht auf der Linie ihres sonstigen Engagements. ${ }^{73}$ Aber obwohl er als Veteran sich eigentlich dagegen verwahren musste, sein Kampferlebnis mit den Straßenschlachten der SA gleichgesetzt zu sehen, gibt es eine klare Logik in seinem Werk, die diese Entscheidung völlig kohärent erscheinen lässt. Und hier finden wir die entscheidenden Anknüpfungspunkte, die seinen soldatischen Nationalismus an den Nationalsozialismus andocken ließen, sozusagen seinen ganz persönlichen ,Tag von Potsdam'.

\section{DemÜtigung, HeLDENGEDENKEN UND EHRE}

Es gibt in Ettighoffers Gesamtwerk drei zentrale Orientierungsmarker seines Denkens und Fühlens: Ehre, Pflicht und Heldentum. Die letzten beiden werden mehrfach miteinander kurzgeschlossen:

Man lebte seinen Tag und tat seine Pflicht, ohne zu wissen, daß dies alles eigentlich Heldentum war, größer und unzugänglicher, als man es in den Geschichtsbüchern finden konnte. ${ }^{74}$

Gerade weil Ettighoffer in seinem Werk so oft und explizit von ,Heldentum' sprach, ist es wichtig zu verstehen, dass er in der Mehrzahl der Fälle gerade keine Verdienstkreuz, würdigen Einzelaktionen meinte. Vielmehr stelle bereits der normale Frontalltag eine so übermenschliche Leistung dar, dass jeder, der diese Pflichterfüllung leistete, für sich in Anspruch nehmen könne, ein wahrhafter Held zu sein, „ohne [es] zu wissen.“ Der letzte Zusatz ist

\footnotetext{
72 Beaupré (2010: 126).

73 So finden sich unter den Autoren des 1. Bandes beispielsweise Karl Bröger, ein SPDAnhänger, Wolf Durian, dessen Roman Der heitere Fridolin im 3. Reich verboten war, oder Max Barthel, der sich nach 1933 zu den neuen Machthabern bekannte, obwohl diese seine Erzählung Die Mühle zum Toten Mann 1933 auf die Liste der verbrannten Bücher gesetzt hatten.

${ }^{74}$ Ettighoffer (1938: 6).
} 
wichtig, um die Pflichterfüllung als moralische Handlung im Sinne Kants zu verstehen, im Unterschied zu einer Handlung, die um einer Belohnung willen geschieht und daher moralisch von geringerem Wert ist.

Es ist nun genau dieses Verständnis von Heldentum, dass sich die ,Mannschaft' in ihrer Anthologie als ein ,anderes Erinnern' zum Thema setzte. Dies ist der erste Anknüpfungspunkt für Ettighoffer.

Der zweite, noch entscheidende Anknüpfungspunkt steckt in jenem Satz von dem „neue[n] Reich, in dem der Front wieder die Ehre wurde, die die Novemberrepublik ihr versagte. “75 Für all die Opfer, die Soldaten in Erfüllung ihrer Pflicht bringen - so lautet der selbstverständliche Anspruch aller Veteranen - schuldet das Vaterland seinen Söhnen Anerkennung und Ehrerbietung. In Ettighoffers Worten: Heldenverehrung. Diesem Anspruch hat die offizielle Gedenkkultur der Weimarer Republik die kalte Schulter zeigt. Und auf dieses emotionale Defizit antwortet nun die ,Mannschaft'.

Ettighoffers Kriegsbücher sind ein unaufhörlicher Heldengesang, dessen innerer Antrieb verständlich wird, wenn man die Wirkung der ausgebliebenen Heldenverehrung in der öffentlichen Gedenkkultur der Weimarer Republik auf jemanden wie ihn bedenkt. Das Vergessen des erlebten Leidens wird dann identisch mit seiner völligen Sinnlosigkeit. Diese offene Wunde passt zu dem weit verbreiteten Gefühl von Demütigung. Eine einzige Szene aus Kameraden von Zelt 27, die pars pro toto steht, mag dieses Gefühl verdeutlichen.

In Köln, das zu Beginn der 20er Jahre von den Engländern besetzt ist, werden die Polizisten und Veteranen Reißing und Frohne als Wachsoldaten abkommandiert, um ein englisches Offiziersfest abzusichern. Als sie nachts vor dem Gebäude Wache stehen, kommt es zu folgender Reflexion:

Ja, man sieht, wie die da oben leben, wie sie genießen. Die neuzeitliche Tanzmusik, Jazz genannt, schallt weithin über das ganze Stadtviertel. [...] Und das ist alles so bitter und so demütigend, hier wachen zu müssen, mit hungrigem Magen, bis der Sieger genug gespeist, genug genossen, genug getanzt hat. [...]

Weißt du Frohne, wenn ich jetzt hier stehen muss, gedemütigt, klein, uniformiert und bewaffnet wie ein Nachtwächter, eine militärische Karikatur, so tröstet mich der Gedanke, dass diese feinen Herren drinnen damals vor uns gezittert haben. [...] Ja, Frohne, dieses Gefühl, oft genug Sieger gewesen zu sein, wirklicher Siege gegen eine gewaltige Übermacht, ehe uns Hunger und Verrat niederzwangen, das allein Frohne, das muss uns trösten. Sie können uns noch lächerlicher hinstellen, mit einem Holzgewehr und einem Blechsäbel meinetwegen, aber die stolze Rückerinnerung an die Tage unserer Macht, die können sie uns nicht nehmen. ${ }^{76}$

Die stolze Rückerinnerung an die Tage unserer Macht! Klarer lässt sich der Zusammenhang von Demütigung und Heldengedenken kaum formulieren. Ganz anders als bei politisch reflektierenden und argumentierenden

\footnotetext{
${ }^{75}$ Siehe Anmerkung 70.
}

${ }^{76}$ Ettighoffer (1939: 227f). 
Schriftstellern aus dem Umfeld der so genannten Konservativen Revolution wie Ernst Jünger, Franz Schauwecker oder Ernst Niekisch, geht es in Kameraden von Zelt 27 um eine zunächst völlig unpolitische Haltung, die sich auf einige wenige ,Orientierungsemotionen' gründet: man fühlt sich vor allem deutsch, man fühlt sich innerlich dem alten Kaiserreich eher verbunden als der neuen Republik, man fühlt sich verraten und gedemütigt, man fühlt Empörung, Wut und Hass. Gerade weil der Roman Kameraden von Zelt 27 literarisch so schlecht, weil er eine einzige emotionale Empörung ist, eignet er sich, die Identität bildenden Grundstrukturen der ,Schützengrabengemeinschaft' herauszuarbeiten: Ehre, Treue, Kameradschaft, Einigkeit, Verlässlichkeit, Disziplin, Kameradschaft und Empörung über alles, was als Verrat empfunden wird. Aber über allem steht: der Anspruch auf Anerkennung des Vaterlandes und Heldengedenken. Dieses tiefe emotionale Bedürfnis bedienten schließlich die Gedenkkultur und der Veteranenkult der Nazis. Paul Coelestin Ettighoffer ist das Paradebeispiel einer noch zu schreibenden Gefühlsgeschichte der nationalsozialistischen Machtergreifung.

\section{BIBLIOGRAFIE}

Internet-Artikel

SIMON, O. C. Bertelsmann Verlag [online]. Polunbi [letzter Aufruf: 27.10.2020]. Abrufbar unter: <http://www.polunbi.de/inst/bertelsmann-03.html>.

LAMPERT, A. Ettighoffer, Paul Coelestin [online]. Polunbi [letzter Aufruf 27.10.2020]. Abrufbar unter: <http://www.polunbi.de/pers/ettighoffer-01.html>.

ARNTZ, H. D. Der Schriftsteller Ettighoffer [online] [letzter Aufruf 27.10.2020]. Abrufbar unter: <http://www.hans-dieter-arntz.de/der_schriftsteller_ettighoffer.html>.

Primärliteratur

BeumelburG, W. (1929), Sperrfeuer um Deutschland, Oldenburg, G. Stalling. JaCOBSOHN, S. (1919), Die Weltbühne, Band 15/I, Heft 6.

ETTIGHOFFER, P. C. (1931), Gespenster am Toten Mann, Köln, Gilde.

EtTigHOFFer, P. C. (1936), Verdun. Das große Gericht, Gütersloh, Bertelsmann.

ETTIGHOFFER, P. C. (1937a), Gespenster am Toten Mann, Gütersloh, Bertelsmann.

ETTIGHOFFER, P. C. (1937b), Die Infanterie marschiert. Bilder aus dem Leben, Kämpfen und Sterben der deutschen Infanterie, Dortmund/Breslau, Crüwell.

EtTighoffer, P. C. (1938), Sturm 1918. Sieben Tage deutsches Schicksal, Gütersloh, Bertelsmann.

EtTIGHOFFER, P. C. (1939), Kameraden vom Zelt 27, Gütersloh, Bertelsmann.

EtTighOFFER, P. C. (2000), Verdun. Das große Gericht, Augsburg, Bechtermünz.

HAHN-BUTRY, J. (1936), Die Mannschaft. Frontsoldaten erzählen vom Front-Alltag, Bd. $1+2$, Berlin, Limpert.

ReMARQue, E. M. (1929), Im Westen nichts Neues, Berlin, Propyläen.

RENN, L. (1928), Krieg, Frankfurt, Societäts-Druckerei. 


\section{Sekundärliteratur}

BEAUPRÉ, N. (2010), „Die ,Mannschaft' und die Erfindung des ,Frontdichters' des Ersten Weltkriegs", in Nationalsozialismus und Erster Weltkrieg, Krumeich, G. (Hrsg.), Essen, Klartext, 111-126.

FrIEDLÄNDER, S., FREI, N., RENDTORFF, T., WitTMANN, R. (2002), Bertelsmann im Dritten Reich, Gütersloh, Bertelsmann.

Groß, G. P. (2018), Das Ende des Ersten Weltkriegs und die Dolchstoßlegende, Stuttgart, Reclam.

KRUMEICH, G. (Hrsg.) (2010), Nationalsozialismus und Erster Weltkrieg, Essen, Klartext.

KRUMEICH, G. (2011), „Zwischen soldatischem Nationalismus und NS-Ideologie. Werner Beumelburg und die Erzählung des Ersten Weltkriegs", in Burgfrieden und Union sacrée. Literarische Deutungen und politische Ordnungsvorstellungen in Deutschland und Frankreich 1914-1933, HZ (Neue Folge), Band 54, Pyta, W., Kretschmann, C. (Hrsg.), München, Oldenbourg, 295-312.

KRUMEICH, G., PROST, A. (2015), Verdun 1916. Une bataille de légende vue des deux côtés, Paris, Tallandier.

KRUMEICH, G. (2018), Die unbewältigte Niederlage. Das Trauma des Ersten Weltkrieges und die Weimarer Republik, Freiburg, Herder.

MOREAU-TRICHET, C. (2002), „La propagande nazie à l'égard des associations françaises d'anciens combattants de 1934 à 1939", Guerres mondiales et conflits contemporains, I(205), 55-70.

SCHNEIDER, T. (2004), „Bestseller im Dritten Reich“, Vierteljahreshefte für Zeitgeschichte, 1, 77-97.

SCHNEIDER, T. F. (2008), „Einleitung“ zu Die Autoren und Bücher der deutschsprachigen Literatur zum Ersten Weltkrieg 1914-1939. Ein bio-bibliographisches Handbuch, Schriften des Erich Maria Remarque-Archivs, Band 23, hg. v. Schneider, T. F., Heinemann, J., Hischer, F., Kuhlmann, J., Puls, P., Göttingen, V\&R unipress, 7-14. VON HINDENBURG, Generalfeldmarschall (1920), Aus meinem Leben, Leipzig, S. Hirzel. 